\title{
Relationships Between Evacuation Population Size, Earthquake Emergency Shelter Capacity, and Evacuation Time
}

\author{
Xiujuan Zhao ${ }^{1,2,3} \cdot$ Wei Xu ${ }^{1,2,3} \cdot$ Yunjia Ma ${ }^{1,2,3} \cdot$ Lianije Qin $^{1,2,3} \cdot$ Junlin Zhang ${ }^{1,2,3}$ • \\ Ying Wang ${ }^{1,2,3}$
}

Published online: 13 December 2017

(C) The Author(s) 2017. This article is an open access publication

\begin{abstract}
Determining the location of earthquake emergency shelters and the allocation of affected population to them are key issues that face shelter planning and emergency management. To solve this emergency shelter location-allocation problem, evacuation time and the construction cost of shelters-both influenced by the evacuation population size and its spatial distribution-are two important considerations. In this article, a mathematical model with two objectives-to minimize total weighted evacuation time (TWET) and total shelter area (TSA)is allied with a modified particle swarm optimization algorithm to address the problem. The relationships between evacuation population size, evacuation time, and total shelter area are examined using Jinzhan Town in Chaoyang District of Beijing, China, as a case study. The results show that TWET has a power function relationship with TSA under different population size scenarios, and a linear function applies between evacuation population and TWET under different TSAs. The joint relationships of TSA, TWET, and population size show that TWET increases with population increase and TSA decrease, and compared with TSA, population influences TWET more
\end{abstract}

Wei Xu

xuwei@bnu.edu.cn

1 State Key Laboratory of Earth Surface Processes and Resource Ecology, Faculty of Geographical Science, Beijing Normal University, Beijing 100875, China

2 Key Laboratory of Environmental Change and Natural Disaster of Ministry of Education, Beijing Normal University, Beijing 100875, China

3 Academy of Disaster Reduction and Emergency Management, Ministry of Civil Affairs and Ministry of Education, Beijing Normal University, Beijing 100875, China strongly. Given a reliable projection of population change and spatial planning of a study area, this method can be useful for government decision making on the location of earthquake emergency shelters and on the allocation of evacuees to those shelters.

Keywords China, earthquake shelter location - Evacuation population allocation - Total shelter area Total weighted evacuation time

\section{Introduction}

With the development of urbanization, globally increasingly more people are exposed to natural hazards and hazard impacts in urban areas. For example, the urbanization rate in China reached $57 \%$ in 2016 and this is projected to reach $62 \%$ in $2020 .{ }^{1}$ Earthquakes are one of the most serious natural hazards, particularly for urban areas where a great concentration of people and assets exists. Risk analysis and management have been used to analyze the effects of natural hazards and to propose approaches that reduce casualties and losses (Koks et al. 2015). Construction of earthquake emergency shelters is an important way to reduce human casualties; earthquake emergency shelter performance is also an important factor determining disaster impacts - the proper location and allocation of earthquake emergency shelters can effectively reduce the evacuation time for evacuees and greatly improve evacuation efficiency.

To solve the earthquake shelter location-allocation problem, site selection models have been used since 1909 when it was first proposed by Weber (1929). These models

\footnotetext{
${ }^{1}$ https://www.ceicdata.com/en/node/490.
} 
include the P-median model (Hakimi 1964), the P-center model (Hakimi 1965), the set covering model (Toregas et al. 1971), and the maximal covering model (Church and Velle 1974), which have all been modified widely for application to the shelter selection problem. Sherali et al. (1991) first introduced the P-median model to address the problem of locating hurricane and flood disaster shelters. Based on the P-median model, Bayram et al. (2015) studied the problem of earthquake shelter location and population evacuation for Istanbul earthquake disasters with the objective to minimize the total evacuation time. Similarly, the P-center and covering models were also used widely to solve shelter location-allocation problems (Berman and Krass 2002; Dalal et al. 2007; Pan 2010; K1lc1 et al. 2015; Gama et al. 2016). Hierarchical models (Chang et al. 2007; Liu et al. 2009; Widener 2009; $\mathrm{Ng}$ et al. 2010; Widener and Horner 2011; Li et al. 2012; Xu et al. 2018) and multiobjective models (Huang et al. 2006; Alçada-Almeida et al. 2009; Saadatseresht et al. 2009; Barzinpour and Esmaeili 2014; Rodríguez-Espíndola and Gaytán 2015) have been developed as well. In earthquake emergency shelter location-allocation decision making, it is important not only to consider model objectives, but also other conditions such as population change and community location change.

Most earthquake evacuation studies have focused on factors that affect casualties (Dombroski et al. 2006; Jonkman et al. 2009; Zahran et al. 2013; Yu and Wen 2016), or on the relationship between congestion and evacuation time inside buildings (Zhang et al. 2013). Some literature has examined the relationship of evacuation population and evacuation time in the face of disasters. For instance, Sherali et al. (1991) showed that a cumulative population fraction dissipated over time following a threesegment piece-wise linear relationship. Wood and Schmidtlein (2013) and Fraser et al. (2014) both used least-cost distance analyses to study the different evacuation times needed by the evacuees following a tsunami disaster. Kilc1 et al. (2015) proposed a model similar to the P-center model, which maximizes the minimum weight of shelters, provides an objective result at different threshold combination values and evacuation population, as well as describes the effects of other factors, such threshold value for minimum utilization of open shelter areas and maximum pairwise utilization difference of candidate shelter areas. Kongsomsaksakul et al. (2005) proposed a bi-level model based on Stackelberg game theory to solve problems of shelter location and evacuation following flood disasters, presenting relationships between shelter capacity and the number of selected shelters. Bayram et al. (2015) considered traffic flow in a P-median model to minimize evacuation time, describing how evacuation time increased in concert with traffic flow, and discussed the effects of shelter number and tolerance levels on total evacuation time. Most recently, Xu et al. (2018) provided a hybrid bilevel model for earthquake emergency shelter location and allocation by considering the dynamic number of evacuees and its implementation, and the model results were also compared with the ones from multiple objective models. Optimization heuristics algorithms have been introduced to solve these models due to the complexity of the location problem (Li et al. 2009; Hu et al. 2012, 2014; Zhao et al. 2015) that cannot be solved by traditional mathematical methods.

Although numerous studies have proposed models and presented relationships between different factors, few analyses have comprehensively examined the feasibility of results, the relationships amongst all factors, and their effects on the results. Particularly, there has been a very limited number of studies that dealt with the relationships between the number of evacuees, evacuation time, and total shelter area at the community or intermediate spatial scales. All of these factors are important for earthquake emergency shelter location-allocation decision making.

The aim of this study is to analyze the sensitivity of an earthquake emergency shelter location-allocation model and explore the relationships between evacuation population, evacuation time, and total shelter area using the town of Jinzhan in Chaoyang District, Beijing, China, as a case study. First, a multiple objective earthquake emergency shelter location-allocation model is developed. This model minimizes total weighted evacuation time (TWET) and total shelter area (TSA) and considers a number of scenarios. Second, the model is solved using a modified particle swarm optimum (PSO) method (Zhao et al. 2015), and the relationships between various factors are analyzed and suggestions about how to use the results are given.

\section{Data and Methods}

Sources of data for the case study area and data processing, earthquake emergency shelter location-allocation model, and scenarios for modeling are presented in this section.

\subsection{Study Area and Data}

The town of Jinzhan in Chaoyang District, Beijing is taken as a case study area. The town is located in the northeastern suburb of Beijing, has a total area of $50 \mathrm{~km}^{2}$, and contains a population of 58,000 . It is primarily a residential area of $11 \mathrm{~km}^{2}$ with 15 communities. There are 10 candidate sites for earthquake emergency shelters selected from current parks, gardens, and other unoccupied spaces in low earthquake risk areas that are at least $500 \mathrm{~m}$ away from known faults. Each site contains an area of more than $3000 \mathrm{~m}^{2}$ that meets the regulatory minimum established by the Beijing 
Municipal Institute of City Planning and Design (2007). The evacuation paths, location and area of candidate shelters, and community location data were extracted using ArcGIS software 10.0 (ESRI 2010) from the map of Beijing City published by China Cartographic Publishing House in 2011 (Fig. 1a), and the population of communities was provided by the Beijing Bureau of Civil Affairs in 2010 (Fig. 1b). Dijkstra's algorithm (Dijkstra 1959) was then used to obtain the length of the shortest evacuation route from a community to each candidate shelter. The width of each path also was obtained by using Google Earth.

The 10 candidate shelter sites are mainly in the northern part of the study area, and only shelters 1 and 9 are in the southern part of Jinzhan Town. The 15 communities are scattered across the area, with population sizes that range between 455 and 12,858 inhabitants. Similar to the distribution of candidate shelters, most communities are concentrated in the northern part of the town. Only four communities are in the southern part of the study area. There are 740 paths with 521 nodes in the evacuation route network. The shortest road from a community to all of the candidate shelter sites can be obtained from the paths and nodes by using Dijkstra's algorithm, which is expressed in the mathematical model in Sect. 2.2.

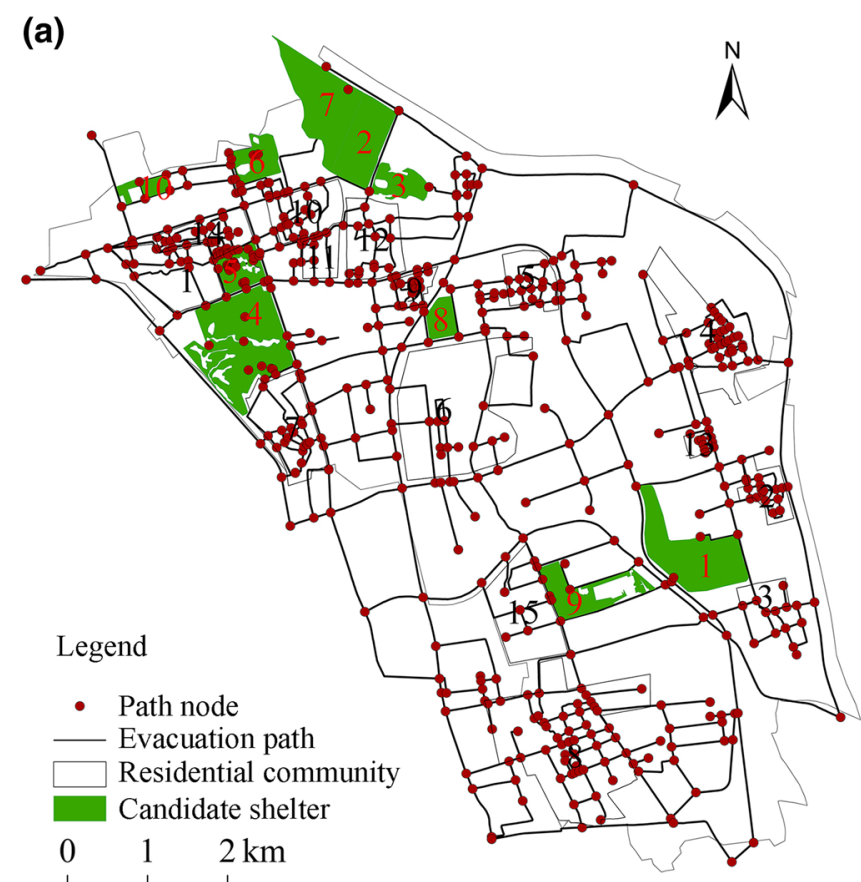

\subsection{Disaster Shelter Location-Allocation Model}

In this study, it is assumed that all residents in a community will be allocated to the same shelter using the shortest evacuation route from the community to the selected shelter. During this process, all the residents in a community evacuate at the same speed, which is determined by consideration of the proportion of children, adults, and elderly in each resident population. As most studies have found, time or duration is the most important factor for evacuation. The best solution is that all evacuees can be allocated to their nearest shelters. This solution is impossible because each shelter can hold only a limited, but variable, number of occupants. Thus, common objectives require minimizing total weighted evacuation time (TWET) - evacuation distance divided by evacuation speed, weighted by the evacuation population divided by the width of an evacuation route-and maximizing the number of people who evacuate to the shelters in a given time. The investment cost incurred to build the shelters is also a very important factor for shelter location and allocation. Shelter size and land value are two key issues that determine the investment cost. In our study, candidate shelter sites are all public lands that are assumed to have the same average land price. Thus shelter development investment is only related to the shelter area. As a result, the objectives selected in this study are to minimize the total shelter area (TSA) of all shelters while assigning each community to a shelter that minimizes TWET. As a rule,

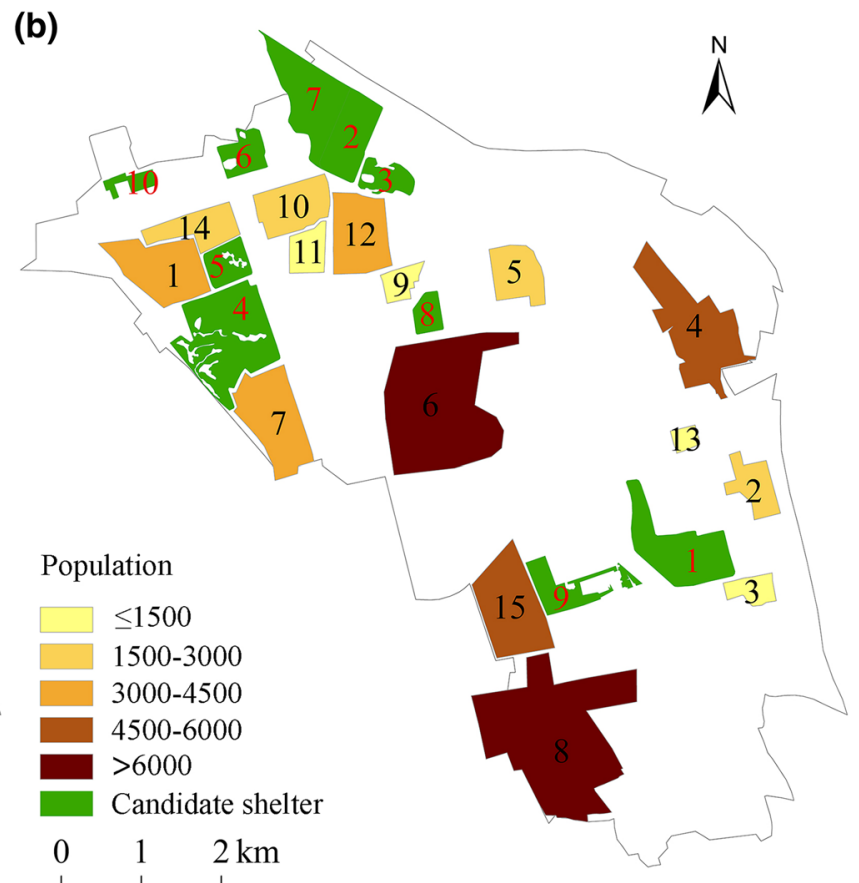

Fig. 1 Location of candidate shelters, communities, and possible evacuation routes (a), and community population (b) in Jinzhan Town, Chaoyang District, Beijing, China 
the capacity limit of each shelter should be observed and the maximum evacuation distance should not be exceeded.

Thus, our objectives are:

$f_{1}=\min \sum_{i=1}^{N} Y_{i} \times S_{i}$

$f_{2}=\min \sum \frac{d_{j i}}{v_{j}} \times \frac{P_{j}}{W_{j i}} \times B_{j i}$

These objectives are subject to:

$$
\begin{aligned}
& \sum_{j=1}^{M} P_{j} L B_{j i}-S_{i} Y_{i} \leq 0 \\
& d_{j i} B_{j i}-D_{j} \leq 0 \quad \forall i=1,2, \ldots, N \quad \forall j=1,2, \ldots, M \\
& \sum_{i=1}^{N} B_{j i} Y_{i}=1 \quad \forall j=1,2, \ldots, M
\end{aligned}
$$

account to ensure that all residents can be housed. Therefore, the two key constraints are distance and capacity.

Equation 3 formulates the capacity constraint, which ensures that the capacity of a selected shelter can meet the demands of residents, while Eq. 4 expresses the distance constraint, affirming that the distance between communities to a selected shelter is less than the maximum evacuation distance. Equation 5 makes sure that all residents in a given community can be only allocated to the same shelter, and Eqs. 6 and 7 mean that the decision variables $B_{i j}$ and $Y_{i}$ have binary values, 0 or 1 .

To solve the aforementioned model, optimization heuristics are applied as the model is complex. The particle swarm optimum (PSO) algorithm is one of the popular optimization heuristics for solving complex problems in many fields, such as in computer science (Yin et al. 2007) and the social sciences (Cai et al. 2014), and it has been applied to solve the problems of facility selection (Ghaderi

$B_{j i}= \begin{cases}1, & \text { Community } j \text { selects candidate shelter } i \text { as emergency shelter } \\ 0, & \text { Community } j \text { does not select candidate shelter } i \text { as emergency shelter }\end{cases}$

$Y_{i}=\left\{\begin{array}{l}1, \quad \text { the candidate shelter } i \text { is selected as earthquake emergency shelter } \\ 0, \quad \text { the candidate shelter } i \text { is not selected as earthquake emergency shelter }\end{array}\right.$

The variables, sets, and parameters in the model are as follows: $I$ is the set of candidate facilities, $I=(1,2, \ldots i$, $\ldots N)$, where $N$ is equal to 10 in this study; $J$ is the community set, $J=(1,2, \ldots j, \ldots M)$, where $M$ is equal to 15 in this study; $S_{i}$ is the area of the candidate shelter $i$; $L$ is the smallest refuge area per capita $\left(1 \mathrm{~m}^{2} /\right.$ person $) ; d_{j i}$ is the length of the shortest route between community $j$ and the candidate shelter $i ; v_{j}$ is the evacuation speed of the evacuation population group in the $j$ th community; $D_{j}$ is the maximum evacuation distance for community $j ; W_{j i}$ is the mean width of the route from community $j$ to the candidate shelter $i$, which is the weighted sum of the width of all paths that form the route; and $P_{j}$ is the number of people who need to be evacuated in community $j$.

The two objectives formulated by Eqs. 1 and 2 minimize TSA and TWET. It should be noted that the unit of the TWET is weighted seconds, which also takes into account the width of the evacuation route and the evacuation population in addition to the travel length and speed. In this study, evacuation speed is set according to the work of Gates et al. (2006). To make shelter allocation success more likely, shelter capacity or service area also needs to be taken into et al. 2012), redundancy allocation (Yeh 2009), and location routing (Marinakis and Marinaki 2008). The algorithm has also been used to solve earthquake disaster shelter location and allocation problems by adding multiple objectives, strict constraints, and discrete feasible domains (Hu et al. 2012; Zhao et al. 2015). Thus, in this study, the modified PSO algorithm proposed by Zhao et al. (2015) is used to solve the shelter location problem.

After solving the model with the PSO algorithm, a set of Pareto solutions are obtained. There are a set of solutions included in a Pareto set as proposed by Pareto, in which a selected solution is feasible and no other feasible solutions dominate it. For each solution in this research, the values of TWET and TSA are included. As well, the locations of shelter sites selected are given. Each result also has an allocation scheme that presents how a community is allocated to a shelter.

\subsection{Change in Evacuation Population Size}

The evacuation population, which is the total population of a community in our study, is an important characteristic that impacts decisions about shelter location and allocation. 
(a)

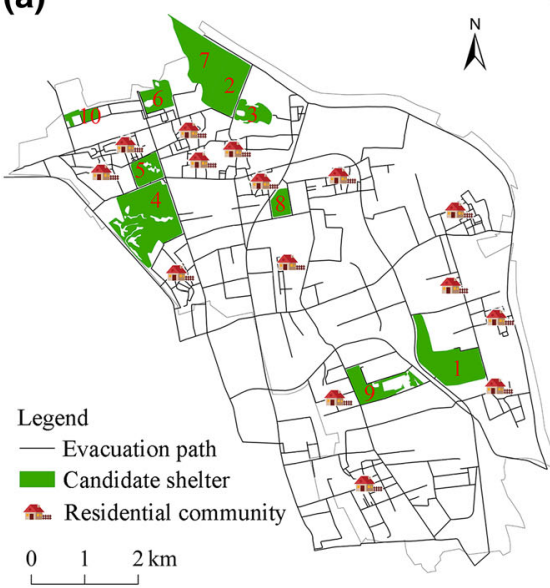

(b)

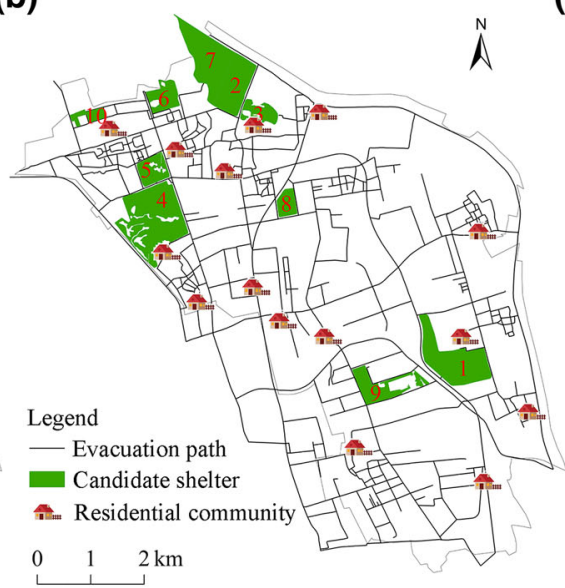

(c)

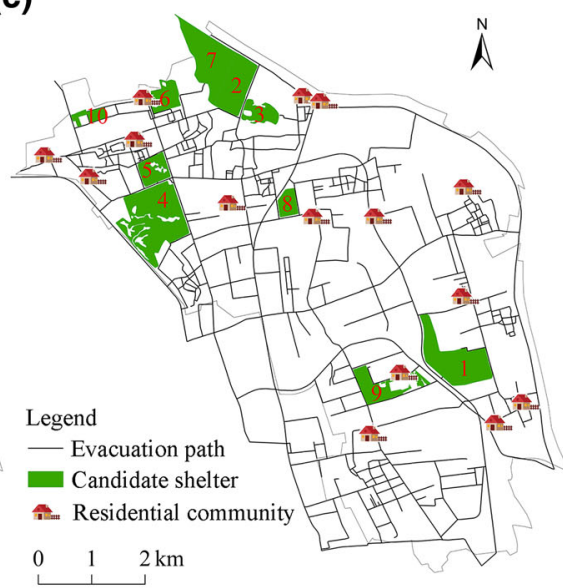

Fig. 2 Community location scenarios. a Location 1, the current locations; b Location 2 and $\mathbf{c}$ Location 3, scenarios generated using ArcGIS

Most studies that consider the effect of population change on evacuation have dealt with evacuation behavior in buildings or at small scales (Johansson et al. 2008; Moussaïd et al. 2011; Kady 2012). In some studies, only the current situation is considered when analyzing how many people can be evacuated within a certain time. In order to select suitable shelters to provide refuges for people in disasters, it is vital to take into consideration any changes in evacuation population size. Few studies have addressed this issue, and population studies at the microscale cannot be references because of the complexity and different objectives of the shelter location-allocation problem. Therefore in order to analyze how evacuation population size will affect shelter capacity planning and the evacuation time of residents, this study assumes population increase by a number of increments until the capacity of a given shelter is exceeded.

\subsection{Change in Community Location}

The location of communities can be changed as city planning is transformed, although this is likely to occur only in places away from mature urban centers. When communities' locations have changed, will the relationships between variables in our model-evacuation population, TWET, and TSA-persist? How will residents' shelter assignment in the planning scheme change? What adjustments should be made to satisfy the demand for earthquake emergency shelters? To obtain answers to these questions, in addition to the current community locations (Location 1, Fig. 2a), two other community location scenarios were randomly generated for the study area using ArcGIS, keeping the shelter area unchanged (Fig. 2b, c).

\subsection{Scenarios of Objectives and Population Condition}

To answer the question of how evacuation population size will affect shelter capacity planning and the evacuation time of residents, four groups of scenarios (10 in total) are analyzed in this study. Details of these scenarios are shown in Table 1.

As mentioned in Sect. 2.2, TWET and TSA is obtained with a set of Pareto solutions under the three Locations with different population sizes. The first Scenario Group (I) looks at the relationship between shelter capacity and evacuation time, and includes two scenarios, which encompass the relationship between TSA and TWET with the current and different hypothetical evacuation popula-

Table 1 Objectives and population condition scenarios used in this study

\begin{tabular}{|c|c|}
\hline $\begin{array}{l}\text { Scenario } \\
\text { group }\end{array}$ & Scenarios of objectives and population condition \\
\hline I & $\begin{array}{l}\text { TWET and TSA with current population } \\
\text { TWET and TSA under different population } \\
\text { scenarios }\end{array}$ \\
\hline II & $\begin{array}{l}\text { Population and TWET with different TSAs } \\
\text { Population and minimum TWET }\end{array}$ \\
\hline III & $\begin{array}{l}\text { Population and minimum TSA } \\
\text { Population and minimum shelter area per capita } \\
\text { Population and maximum shelter area per capita }\end{array}$ \\
\hline IV & $\begin{array}{l}\text { Population, minimum TWET, and maximum TSA } \\
\text { Population, maximum TWET, and minimum TSA } \\
\text { Population, TWET, and TSA }\end{array}$ \\
\hline
\end{tabular}



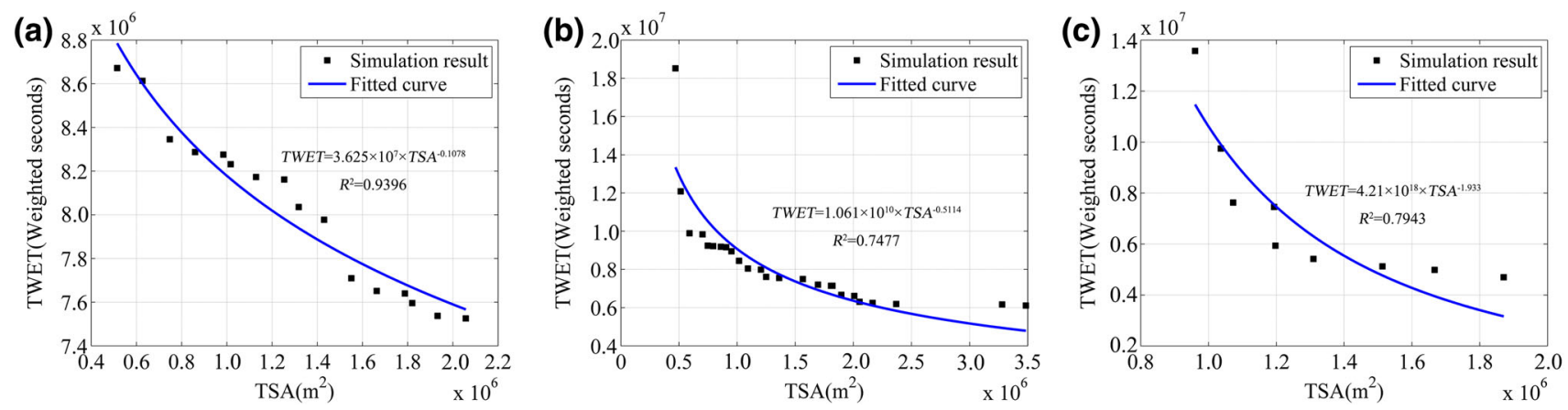

Fig. 3 Relationships between total weighted evacuation time (TWET) and total shelter area (TSA) with current evacuation current community locations; b Location 2 and c Location 3, community location scenarios generated using GIS population and different community locations. a Location 1, the

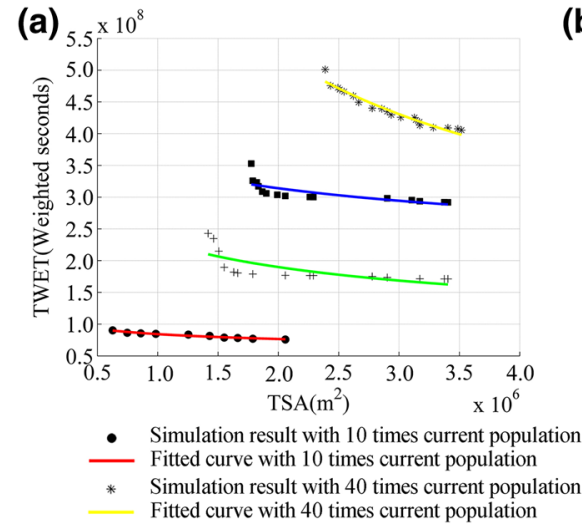

Fig. 4 Relationships between total shelter area (TSA) and total weighted evacuation time (TWET) at various evacuation population levels with different community locations. a Location 1, the current

tion levels. The second Scenario Group (II) considers the relationship between evacuation population and evacuation time, including two scenarios. The first scenario analyzes the relationships between evacuation population and TWET with different TSAs. A set of Pareto solutions can be obtained with each population size. To examine how population size affects the minimum TWET among the Pareto solutions, the second scenario of Scenario Group (II) analyzes the relationship between evacuation population and minimum TWET. The third Scenario Group (III) considers the relationship between evacuation population and shelter area, and includes three scenarios that examine the relationships between evacuation population and minimum TSA, and evacuation population and minimum/maximum shelter area per capita. In the fourth Scenario Group (IV), relationships between the three factors are considered, including three scenarios that explore the relationships between evacuation population, minimum TWET, and maximum TSA; between evacuation population, maximum TWET, and minimum TSA; and between evacuation population, TWET, and TSA.

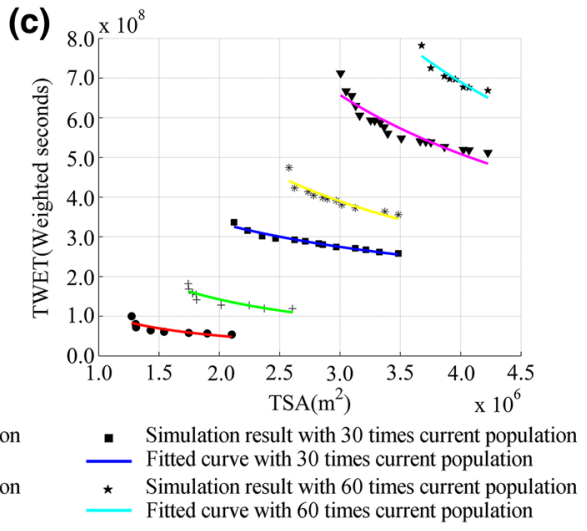

community locations; b Location 2 and c Location 3, community location scenarios generated using GIS

\section{Results}

In this section, the relationship between TWET and TSA, evacuation population size and TWET, and evacuation population and TSA are presented and analyzed.

\subsection{Total Weighted Evacuation Time (TWET) and Total Shelter Area (TSA)}

To explore the relationship between evacuation time and shelter area, different scenarios that consider current evacuation population and changes in evacuation population size were considered. The results are shown in Figs. 3 and 4 respectively. In both figures, (a) shows the result using the current community locations, and (b) and (c) show the results under community location scenarios illustrated in Fig. 2b, c. It is found that TWET and TSA are negatively correlated no matter how large the evacuation population is. TWET decreases as TSA increases for all community location scenarios with different evacuation population sizes, and the decrease slows down when TSA 
Table 2 Estimated parameter values of TWET and TSA relationship for different evacuation population size and community location scenarios

\begin{tabular}{|c|c|c|c|c|}
\hline Location & Evacuation population (times of current population) & $a_{0}$ & $a_{1}$ & $\mathrm{R}^{2}$ \\
\hline \multirow[t]{4}{*}{ Location 1} & 10 & $5.638 \mathrm{e}+08$ & -0.1376 & 0.9550 \\
\hline & 20 & $1.332 \mathrm{e}+10$ & 0.2929 & 0.5353 \\
\hline & 30 & $3.174 \mathrm{e}+09$ & -0.1595 & 0.5526 \\
\hline & 40 & $6.726 \mathrm{e}+11$ & -0.4931 & 0.9503 \\
\hline \multirow[t]{6}{*}{ Location 2} & 10 & $2.995 \mathrm{e}+11$ & -0.5817 & 0.8167 \\
\hline & 20 & $3.511 \mathrm{e}+10$ & -0.3774 & 0.7888 \\
\hline & 30 & $3.018+16$ & -1.2470 & 0.8964 \\
\hline & 40 & $6.171 \mathrm{e}+12$ & -0.6394 & 0.9299 \\
\hline & 50 & $7.905 \mathrm{e}+12$ & -0.6233 & 0.6257 \\
\hline & 60 & $2.774 \mathrm{e}+11$ & -0.3791 & 0.8741 \\
\hline \multirow[t]{6}{*}{ Location 3} & 10 & $3.619 \mathrm{e}+14$ & -1.0880 & 0.6967 \\
\hline & 20 & $2.130 \mathrm{e}+14$ & -0.9800 & 0.7798 \\
\hline & 30 & $4.071 \mathrm{e}+11$ & -0.4895 & 0.9600 \\
\hline & 40 & $7.083 e+13$ & -0.8120 & 0.8405 \\
\hline & 50 & $3.861 \mathrm{e}+14$ & -0.8906 & 0.8593 \\
\hline & 60 & $9.147 \mathrm{e}+15$ & -1.0790 & 0.8377 \\
\hline
\end{tabular}
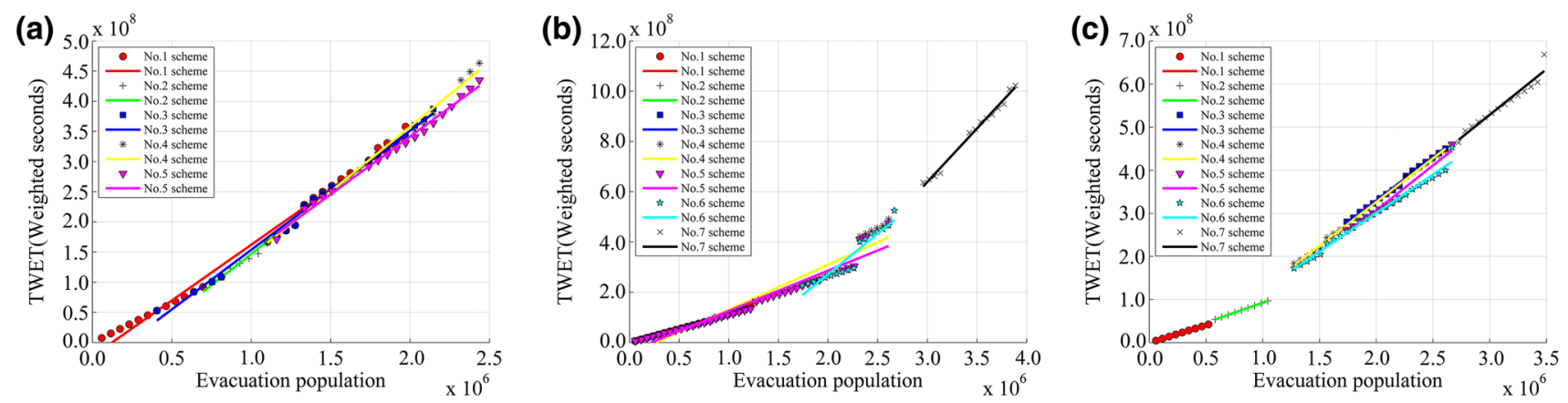

Fig. 5 Relationships between evacuation population and total weighted evacuation time (TWET) with different total shelter areas (TSAs). ac Location 1, Location 2, and Location 3, respectively

further increases. This means that although increasing shelter area is an effective way to shorten the evacuation time for people, its efficiency decreases as total shelter area increases. This indicates that when TSA is large enough, merely investing more to increase shelter area is not a useful way to shorten the evacuation time if other conditions remain unchanged. Other measures, such as changing shelter locations or building more shelters, might be more effective and should be prioritized when making shelter location and allocation plans.

According to the trends shown in Figs. 3 and 4, the fit of a power function was used to quantitatively characterize the relationships between TWET and TSA:

$T W E T=a_{0}(T S A)^{a_{1}}$

where $T$ is the value of TWET, $S$ is the value of TSA, and $a_{0}$ and $a_{1}$ are parameters decided by evacuation population size and community location. The values of estimated parameters for the fitting lines in Fig. 4 for different community location and population scenarios are shown in Table 2. High values of $\mathrm{R}^{2}$ (measure of goodness-of-fit) indicate that the power function with the parameters presented in Table 2 can show the relationship between TSA and TWET well, and these two variables are highly correlated. The values of the parameter $a_{1}$ are less than zero for all scenarios, which indicates that TWET decreases as TSA increases. The values of $\mathrm{R}^{2}$ are larger than 0.50 for most scenarios (more than 0.95 in some scenarios). That means the power function relationship is the best fit and robust for all scenarios.

\subsection{Evacuation Population Size and Total Weighted Evacuation Time (TWET)}

Figure 5 shows the relationships between TWET and evacuation population size with different TSA and 
Table 3 Estimated parameter values of total weighted evacuation time (TWET) and evacuation population relationship for different total shelter area (TSA) and community location scenarios

\begin{tabular}{|c|c|c|c|c|c|}
\hline Location & Scheme ID & TSA $\left(m^{2}\right)$ & $\mathrm{b}_{1}$ & $\mathrm{~b}_{2}$ & $\mathrm{R}^{2}$ \\
\hline \multirow[t]{5}{*}{ Location 1} & 1 & $2,057,213$ & 185.0 & $-2.283 \mathrm{E}+07$ & 0.9891 \\
\hline & 2 & $2,260,830$ & 206.6 & $-5.979 \mathrm{E}+07$ & 0.9967 \\
\hline & 3 & $2,290,098$ & 197.5 & $-4.387 \mathrm{E}+07$ & 0.9946 \\
\hline & 4 & $2,902,392$ & 214.7 & $-7.165 E+07$ & 0.9918 \\
\hline & 5 & $3,404,735$ & 192.2 & $-4.264 \mathrm{E}+07$ & 0.9932 \\
\hline \multirow[t]{7}{*}{ Location 2} & 1 & $2,053,257$ & 118.6 & $-3.586 \mathrm{E}+06$ & 0.9967 \\
\hline & 2 & $2,165,409$ & 117.6 & $-3.852 \mathrm{E}+06$ & 0.9966 \\
\hline & 3 & $2,369,027$ & 112.5 & $-1.932 \mathrm{E}+06$ & 0.9986 \\
\hline & 4 & $3,280,046$ & 178.9 & $-4.826 \mathrm{E}+07$ & 0.9415 \\
\hline & 5 & $3,483,663$ & 160.3 & $-3.454 \mathrm{E}+07$ & 0.9427 \\
\hline & 6 & $3,720,504$ & 322.4 & $-3.729 E+08$ & 0.9098 \\
\hline & 7 & $4,225,630$ & 425.5 & $-6.375 E+08$ & 0.9911 \\
\hline \multirow[t]{7}{*}{ Location 3} & 1 & $1,870,639$ & 81.0 & 0 & 1 \\
\hline & 2 & $2,103,524$ & 92.5 & 0 & 1 \\
\hline & 3 & $2,856,867$ & 200.4 & $-7.085 \mathrm{E}+07$ & 0.9964 \\
\hline & 4 & $2,893,240$ & 203.2 & $-8.020 \mathrm{E}+07$ & 0.9982 \\
\hline & 5 & $3,326,558$ & 208.0 & $-1.087 \mathrm{E}+08$ & 0.9758 \\
\hline & 6 & $3,483,663$ & 179.0 & $-5.733 \mathrm{E}+07$ & 0.9880 \\
\hline & 7 & $4,225,630$ & 211.7 & $-1.063 \mathrm{E}+08$ & 0.9401 \\
\hline
\end{tabular}
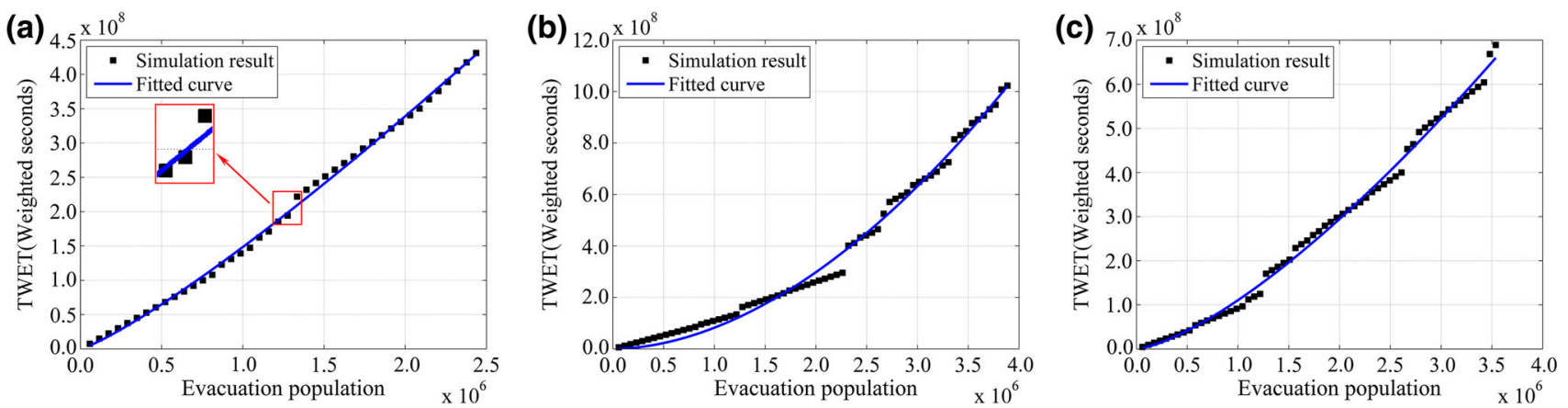

Fig. 6 Relationships between evacuation population and minimum total weighted evacuation time (MIT). a-c Location 1, Location 2, and Location 3, respectively

community locations. Colored point signs are simulation results, and colored lines are the fitted curves with Eq. 9. The details of schemes denoted in Fig. 5 are presented in Table 3. Taking Fig. 5a as an example, there are five different values of TSA for Pareto solutions obtained, so there are five schemes for the current community locations.

Figure 5 shows that evacuation population and TWET are highly correlated, and, for all scenarios with different TSAs, TWET increases as evacuation population increases. To explore quantitatively the relationships between evacuation population and TWET, the following linear-fitting method was applied:

$T=b_{1} P+b_{2}$ where $P$ is the size of evacuation population, and $b_{1}$ and $b_{2}$ are parameters for different scenarios whose values are shown in Table 3. The $\mathrm{R}^{2}$ values exceed 0.9 in all cases, which means that the equation used for estimations is reasonable.

For most scenarios, the values of $b_{1}$ are between 100 and 250, which means that TWET increases as evacuation population increases. The $b_{1}$ values generally show an increasing trend when TSA increases, which means that TWET increases more quickly corresponding to the increase of evacuation population with higher TSAs.

To further explore the relationship between evacuation population and evacuation time, the relationships between 
evacuation population and minimum total weighted evacuation time $(M I T)$ was examined and the results are shown in Fig. 6 (See also Eq. 13). The $\mathrm{R}^{2}$ values of fitting lines with $95 \%$ confidence intervals are all larger than 0.95 , which indicates that MITs are highly correlated with the evacuation population and the fitting function shown in the figure is effectively fitted. The results show that if the allocation scheme is not changed, MIT will increase as the evacuation population increases. But if the allocation scheme changes, MIT will increase suddenly under the effects of both shelter assignment and population allocation scheme change and evacuation population increases such as the situation shown in the red box in Fig. 6a. To ensure the safety of evacuees, TWET should be as short as possible. According to the relationship shown in Fig. 6, more improvement to the current shelter planning is needed with the increase of evacuation population size, especially when the MIT exceeds their tolerance.

\subsection{Evacuation Population and Shelter Area}

TSA is an important parameter that reflects the cost of building shelters. The changes of minimum TSA (MIA) for scenarios with different evacuation population sizes are shown in Fig. 7. One clear feature of these results is that there is a linear positive relationship between minimum TSA and evacuation population. This indicates that the government needs to invest more to expand shelter capacities when the evacuation population increases, and the investment growth rate can be the same as the rate of evacuation population increase.

Besides the cost for building shelters, the comfort level of evacuees is another indicator to compare the different solutions. Large area shelters with adequate facilities, food, water, medical care, and private space are comfortable and favored by evacuees. Thus, to explore the change in comfort level for evacuees, minimum shelter area per capita (MIAA) and maximum shelter area per capita
(MAAA) under different population scenarios were calculated according to Eqs. 10 and 11, respectively.

$M I A A=\min \left(T S A / \sum_{j=1}^{M} P_{j}\right)$

$M A A A=\max \left(T S A / \sum_{j=1}^{M} P_{j}\right)$

The relationships of evacuation population and MIAA, and evacuation population and MAAA are shown in Fig. 8a1-c1, a2-c2, respectively. There are clear power function relationships between MIAA or MAAA and the evacuation population; as the evacuation population increases, both MIAA and MAAA decrease, and the rate of this decrease slows down until the shelter area per capita reaches nearly 0 . At the beginning of an evacuation, values of MIAA are more than 8 for the three location scenarios, which indicates that there is enough space for potential evacuees, and their comfort level is high. As well, different location-allocation solutions can be selected as the available MAAA is much larger than MIAA. With an increase of evacuation population, both MIAA and MAAA decrease quickly to around 1 . This shows that there is only basic space for evacuees to stay and their comfort level gets lower. Meanwhile, the selection of shelter locationallocation solutions is limited.

\subsection{Joint Analyses of Evacuation Population, Total Shelter Area (TSA), and Total Weighted Evacuation Time (TWET)}

This section discusses the joint relationships between evacuation population, total shelter area (TSA), and total weighted evacuation time (TWET). The relationships of evacuation population, minimum TSA (MIA), and maximum TWET (MAT), as well as evacuation population, minimum TWET (MIT), and maximum TSA (MAA) are first presented. Then, the joint relationships between
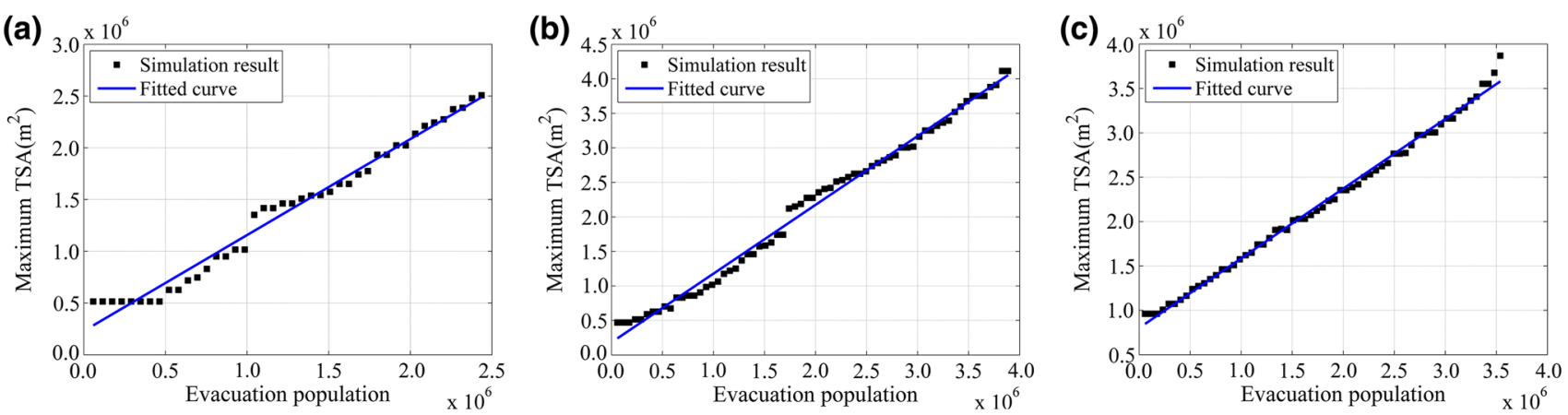

Fig. 7 Relationships between evacuation population and minimum total shelter area (MIA). a-c Location 1, Location 2, and Location 3, respectively 

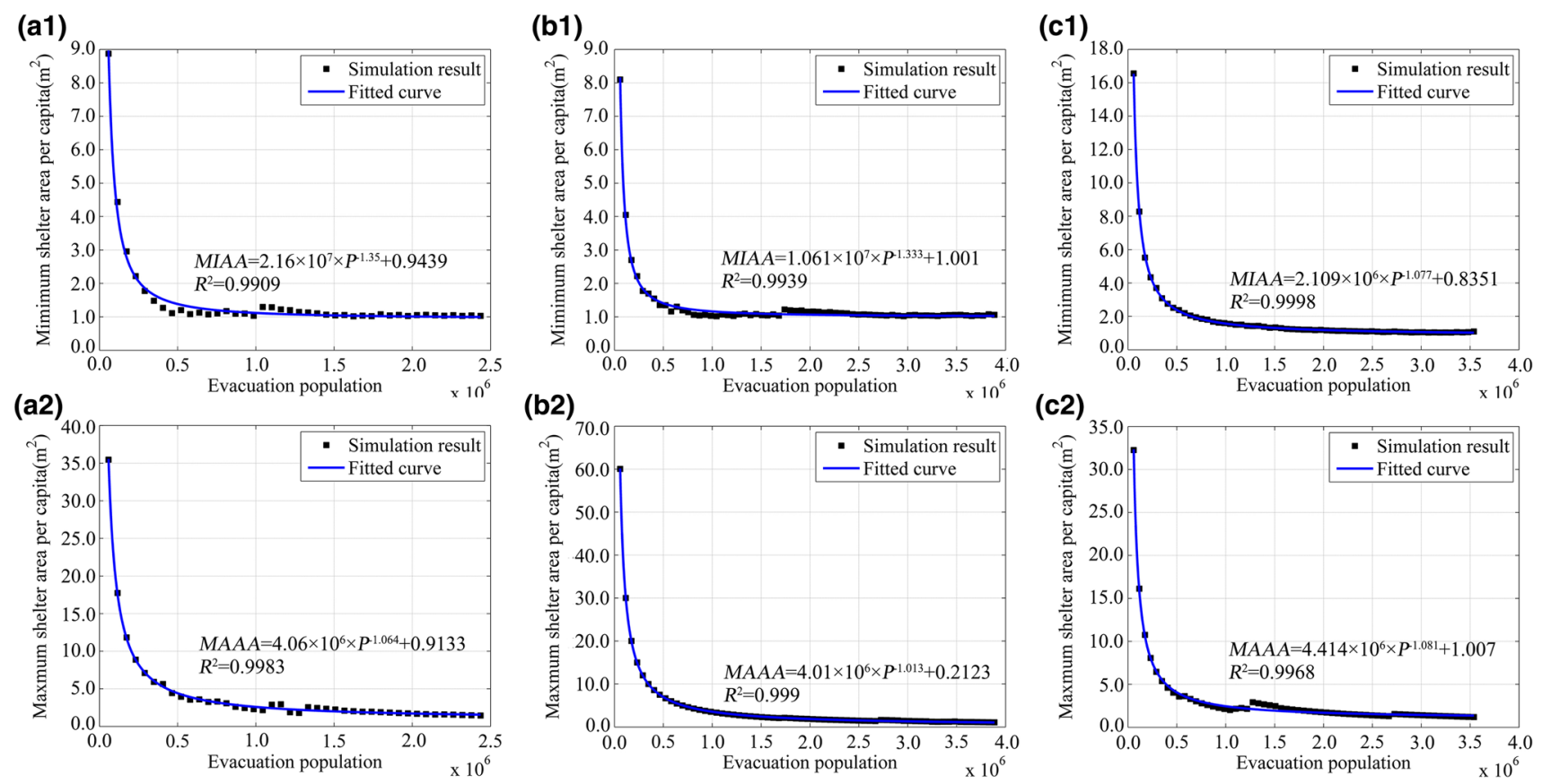

Fig. 8 Relationships between evacuation population and minimum shelter area per capita (MIAA) and evacuation population and maximum shelter area per capita (MAAA). a1-a2 Location 1, b1-b2 Location 2, and c1-c2 Location 3, respectively

evacuation population, TSA, and TWET are analyzed. Finally, their potential application is proposed.

\subsubsection{Evacuation Population, Minimum Total Shelter Area (MIA), and Maximum Total Weighted Evacuation Time (MAT)}

From the analysis presented above, it is clear that MIA is positively correlated with evacuation population. However, MIA always combines with maximum TWET. Thus, a linear-fitting method, as shown in Eq. 12, was used to analyze quantitatively the relationships between MIA, evacuation population, and MAT, and the scenario results describing the relationships between them are shown in Fig. 9. The $\mathrm{R}^{2}$ values for these three trend surfaces are $0.9889,0.9652$, and 0.9702 , respectively, at $95 \%$ confidence levels-it means that these three models fit effectively.

$M A T=k_{0}+k_{1} P+k_{2} M I A$

where $\mathrm{k}_{0}, \mathrm{k}_{1}$, and $\mathrm{k}_{2}$ are parameters for different scenarios whose values are shown in Fig. 9. As key stakeholders, evacuees and the government both want lower TWET to ensure the safety of the evacuees. However, the evacuees only want to be evacuated and relieved of anxiety and stress as quickly as possible, while the government also wants to invest less in constructing shelters. Thus, within the tolerances of MAT for both the government and evacuees, the government can determine whether the solution with MIA is suitable within the population changes according to the relationships among the three factors in Fig. 9. (a)

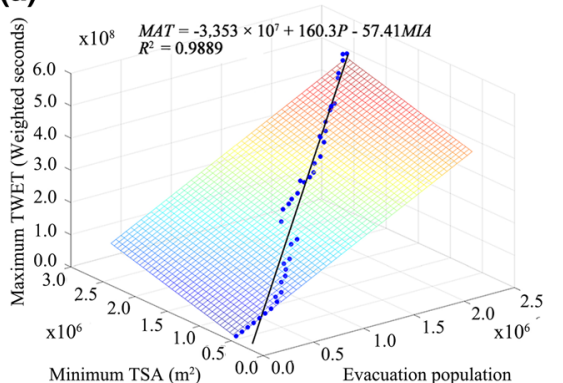

(b)

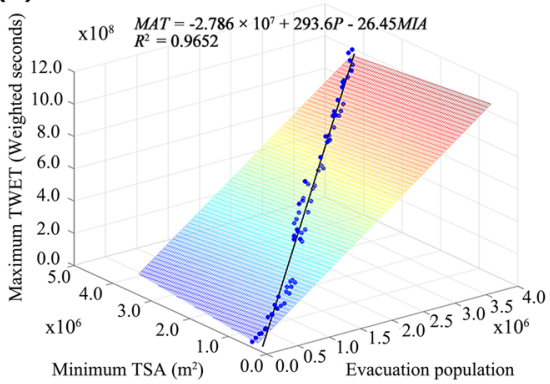

(c)

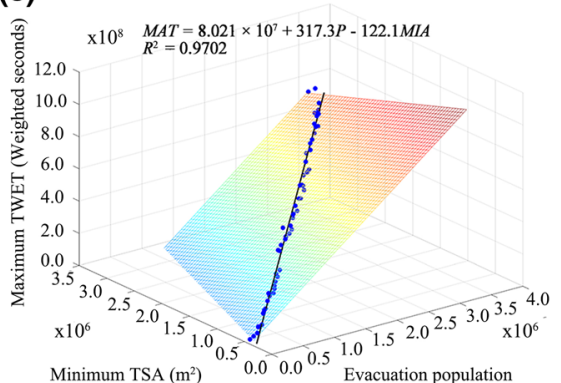

Fig. 9 Fitting surfaces of maximum total weighted evacuation time (MAT), minimum total shelter area (MIA), and evacuation population. ac Location 1, Location 2, and Location 3, respectively 


\subsubsection{Evacuation Population, Maximum Total Shelter Area (MAA), and Minimum Total Weighted Evacuation Time (MIT)}

Results of the relationships between evacuation population, maximum TSA (MAA), and minimum TWET (MIT) for the three community location scenarios are shown in Fig. 10. The fitted surfaces describing the relationships between these three factors were generated using Eq. 13:

$M I T=l_{0}+l_{1} P+l_{2} M A A$

where $l_{0}, l_{1}$, and $l_{2}$ are parameters for different scenarios, and their values are shown in Fig. 10.

The $\mathrm{R}^{2}$ of these three trend surfaces are $0.9947,0.9472$, and 0.9814 , respectively, at $95 \%$ confidence levels, which shows that the trend surfaces fit well. With this finding, the most suitable solution can be determined within the maximum investment that the government could provide.

\subsubsection{Evacuation Population, Total Shelter Area (TSA), and Total Weighted Evacuation Time (TWET)}

To explore the joint relationships between evacuation population, TSA, and TWET, all scenario results were plotted into a three-dimensional coordinate system. The simulation results distribution and interpolation of these plots for the three community location scenarios are shown in Fig. 11. It can be seen that the simulation result distribution varies by stages with evacuation population changes. As well, the number of simulation results is less in the space with high values of all three axes.

To further study the stage characteristics, the relationships are presented between TWET and evacuation population, and between TSA and evacuation population, respectively, in Figs. 12 and 13, respectively. Figure 12 shows that the TWET of all three community location scenarios has obvious boundaries, as simulation results are distributed between the trend lines of minimum and maximum TWET. In addition, these simulation results have obvious stage characteristics, as seen in the box in
Fig. 12b, especially with regard to Location 2 and Location 3 scenarios, which depend on the changing character of minimum TWET. Usually, a sudden TWET increase happens when the evacuation population exceeds the capacity of shelters available under the current situation.

TSA for all three community location scenarios has clear lower boundaries, marked by the trend lines of minimum TSA as shown in Fig. 13. These simulation results are distributed equally and are concentrated when TSA is small. They become more dispersed as TSA increases. It can also be seen that simulation results on some TSAs that exist under certain evacuation population scenarios are not present, such as the simulation results in the red box in Fig. 13a. For solutions with the same TSA, when the size of the evacuation population exceeds the capacity of the selected shelters, the TWET caused by the assignment of excess population to a large shelter area might be longer than the one with a small TSA. Thus, the solution is not a nondominated result. However, when the evacuation population continues to increase to another level, the TWET is less than the one with small TSA, thus, the result with that TSA that disappeared is a nondominated result again.

Figure 14 shows the fitted surfaces of TWET against TSA and evacuation population as calculated using Eq. 14:

$T W E T=q_{0}+q_{1} P+q_{2} T S A$

where $\mathrm{q}_{0}, \mathrm{q}_{1}$, and $\mathrm{q}_{2}$ are parameters for different scenarios and their values are shown in Fig. 14.

In these fitted surfaces, the relationships between TWET, evacuation population, and TSA are clearly presented. It can be seen that TWET increases with population increase and TSA decrease, and, compared with TSA, population influences TWET more strongly. The number of solutions in each stage also becomes smaller as population increases. By considering the distance constraint, along with the tolerance of government for TSA, the best solution under different population sizes can be determined quickly according to this surface. Also the surface can help the government to check whether the existing shelter location and allocation plans are suitable. (a)

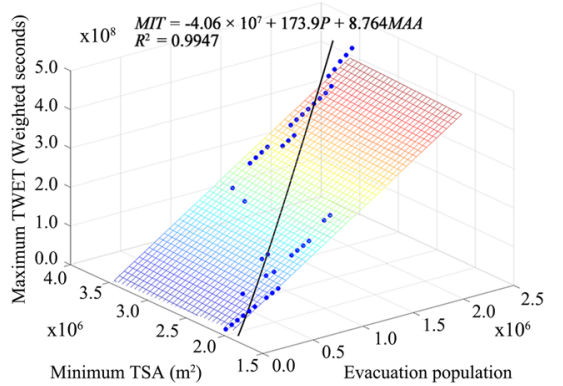

(b)

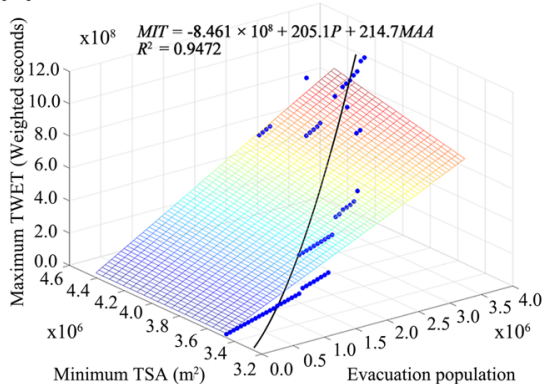

(c)

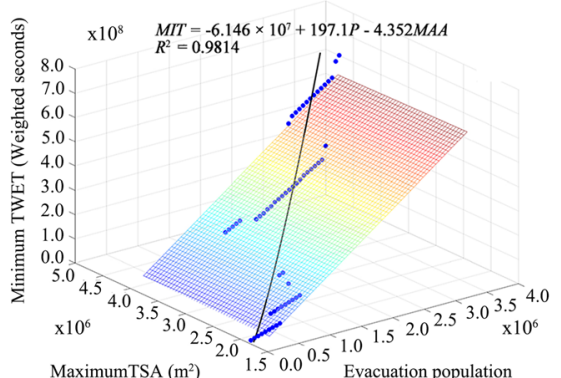

Fig. 10 Fitting surfaces of minimum total weighted evacuation time (MIT), maximum total shelter area (MAA), and evacuation population. ac Location 1, Location 2, and Location 3, respectively 
(a)

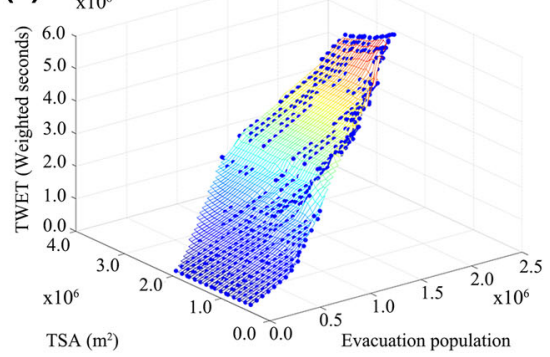

(b)

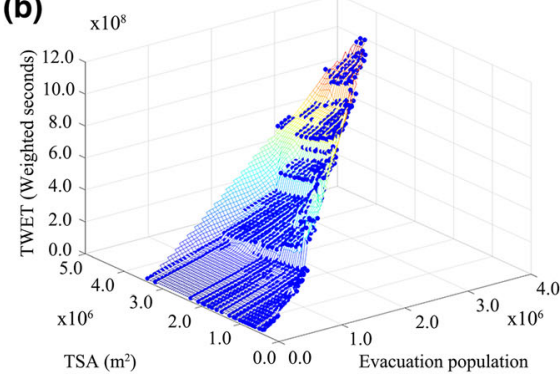

(c)

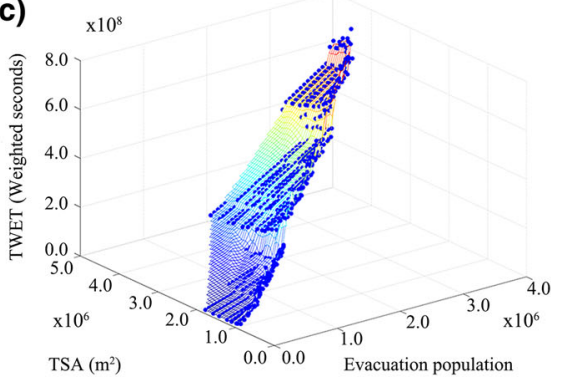

Fig. 11 Distribution and interpolation of the simulation result values of evacuation population, total shelter area (TSA), and total weighted evacuation time (TWET) joint relationship. a-c Location 1, Location 2, and Location 3, respectively
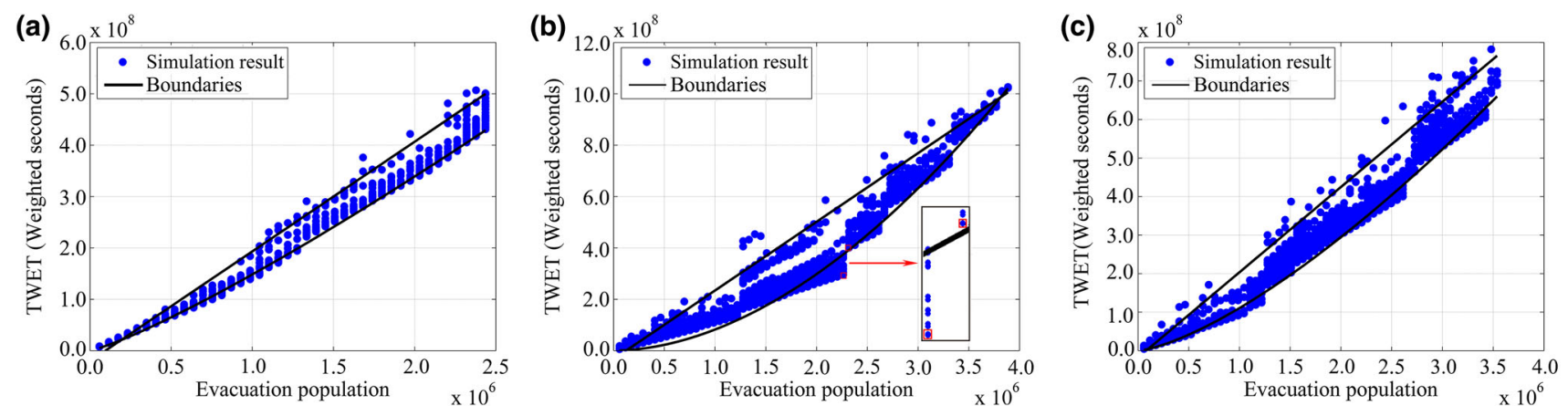

Fig. 12 Relationships between evacuation population and total weighted evacuation time (TWET) based on the joint relationships between population, TWET, and TSA. a-c Location 1, Location 2,
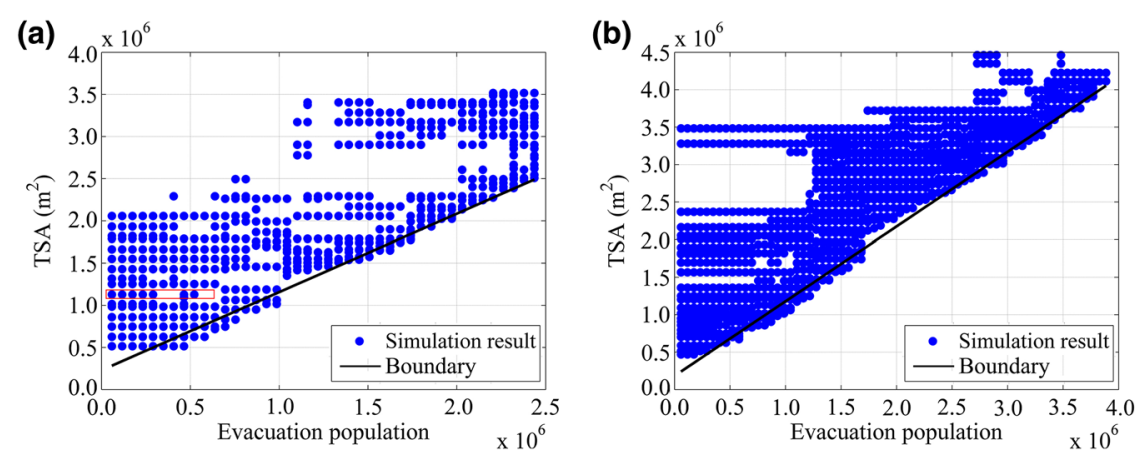

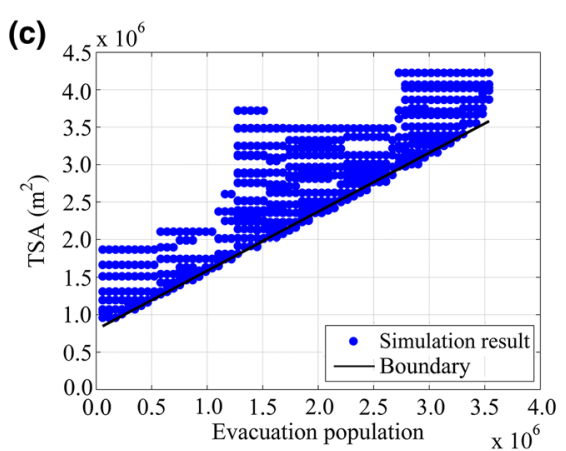

Fig. 13 Relationships between evacuation population and total shelter area (TSA) based on the joint relationships between population, total weighted evacuation time (TWET), and TSA. a-c Location

\section{Conclusions}

In this study, the relationships between evacuation population, evacuation time, and shelter area are examined by using scenario analysis and taking Jinzhan Town in Beijing as a case study.

The results show that TWET has a power relationship with TSA. Under certain evacuation population scenarios, TWET will decrease as TSA increases; as the evacuation population increases, the relative effectiveness of TSA to influence TWET decreases. This indicates that with regard and Location 3, respectively. Blue dots are simulation results, and black lines are boundaries
1, Location 2, and Location 3, respectively. Blue dots are simulation results, and black lines are boundaries

to candidate shelter solutions, increasing TSA has lower efficiency in meeting resident demands for earthquake emergency shelters with a larger population.

Minimum values of TWET and TSA both have a clear positive relationship with evacuation population. The joint relationships of minimum TWET (MIT), maximum TSA (MAA), and population; the joint relationships of minimum TSA (MIA), maximum TWET (MAT), and population; and the joint relationships of TSA, TWET, and population are analyzed respectively. Based on these relationships, the evacuation population estimation, and the location and 
(a)

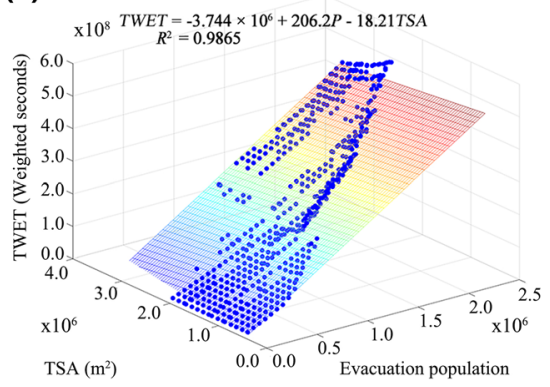

(b)

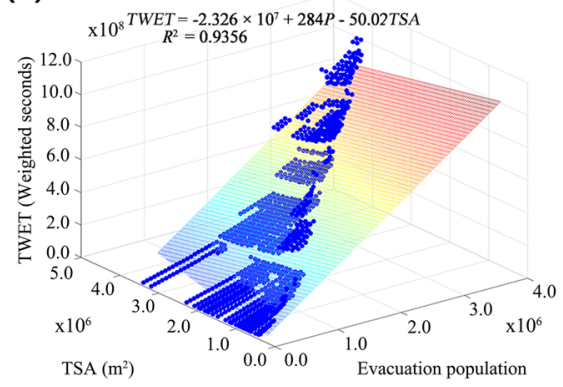

(c)

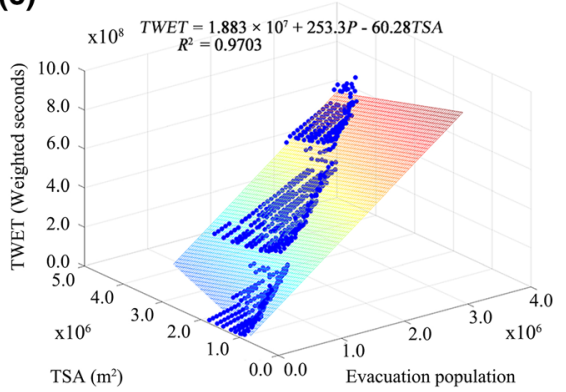

Fig. 14 Surface of evacuation population, total shelter area (TSA), and total weighted evacuation time (TWET) joint relationship. a-c Location 1, Location 2, and Location 3, respectively

probability of future earthquakes, improved earthquake shelter location-allocation schemes can be quickly determined to meet all requirements of the key stakeholderslocal residents and the government. By combining the estimation of population in the future and the planning of the study area, the government can obtain information about the shelter area corresponding with the total evacuation time, which can help to determine how and where to construct shelters.

There are several limitations to this study that can be considered in future work. First, more realistic scenarios of community location and shelter location can be considered as these will definitely affect model results. Sensitivity of the location-allocation model output to change in the objectives should also be examined. Population change in all communities can use more realistic estimations as well. The price of urban land can be considered in the model for a larger study area, since it is important for accurate estimates for the investment budget. The fitting surface also can be improved by using further refined scenarios.

Acknowledgements This study was funded by the Ministry of Science and Technology, China (Grant Number: 2016YFA0602404), Ministry of Education and State Administration of Foreign Experts Affairs, China (Grant Number: B08008), and National Natural Science Foundation of China (Grant Number: 41201547).

Open Access This article is distributed under the terms of the Creative Commons Attribution 4.0 International License (http://crea tivecommons.org/licenses/by/4.0/), which permits unrestricted use, distribution, and reproduction in any medium, provided you give appropriate credit to the original author(s) and the source, provide a link to the Creative Commons license, and indicate if changes were made.

\section{References}

Alçada-Almeida, L., L. Tralhão, L. Santos, and J. CoutinhoRodrigues. 2009. A multiobjective approach to locate emergency shelters and identify evacuation routes in urban areas. Geographical Analysis 41(1): 9-29.

Barzinpour, F., and V. Esmaeili. 2014. A multi-objective relief chain location distribution model for urban disaster management. The
International Journal of Advanced Manufacturing Technology 70(5-8): 1291-1302.

Bayram, V., B.Ç. Tansel, and H. Yaman. 2015. Compromising system and user interests in shelter location and evacuation planning. Transportation Research Part B: Methodological 72: 146-163.

Beijing Municipal Institute of City Planning \& Design. 2007. Planning of earthquake and emergency shelters in Beijing central districts (outdoors). http://xch.bjghw.gov.cn/web/static/ articles/catalog_84/article_7491/7491.html. Accessed 26 Nov 2017 (in Chinese).

Berman, O., and D. Krass. 2002. The generalized maximal covering location problem. Computers \& Operations Research 29(6): 563-581.

Cai, Q., M. Gong, B. Shen, L. Ma, and L. Jiao. 2014. Discrete particle swarm optimization for identifying community structures in signed social networks. Neural Networks 58: 4-13.

Chang, M., Y. Tseng, and J. Chen. 2007. A scenario planning approach for the flood emergency logistics preparation problem under uncertainty. Transportation Research Part E: Logistics and Transportation Review 43(6): 737-754.

Church, R., and C.R. Velle. 1974. The maximal covering location problem. Papers in Regional Science 32(1): 101-118.

Dalal, J., P.K. Mohapatra, and G.C. Mitra. 2007. Locating cyclone shelters: A case. Disaster Prevention and Management 16(2): $235-244$.

Dijkstra, E.W. 1959. A note on two problems in connexion with graphs. Numerische Mathematik 1(1):269-271.

Dombroski, M., B. Fischhoff, and P. Fischbeck. 2006. Predicting emergency evacuation and sheltering behavior: A structured analytical approach. Risk Analysis 26(6): 1675-1688.

ESRI (Environmental Systems Research Institute). 2010. ArcGIS desktop: Release 10. Redlands, CA: ESRI.

Fraser, S.A., N.J. Wood, D.M. Johnston, G.S. Leonard, P.D. Greening, and T. Rossetto. 2014. Variable population exposure and distributed travel speeds in least-cost tsunami evacuation modelling. Natural Hazards and Earth System Science 14(11): 2975-2991.

Gama, M., B.F. Santos, and M.P. Scaparra. 2016. A multi-period shelter location-allocation model with evacuation orders for flood disasters. EURO Journal on Computational Optimization 4(3-4): 299-323.

Gates, T.J., D.A. Noyce, A.R. Bill, and N. Van Ee. 2006. Recommended walking speeds for pedestrian clearance timing based on pedestrian characteristics. 85th Annual Meeting of the Transportation Research Board. Paper No. 06-1826, 2006. https:// pdfs.semanticscholar.org/fc81/aff9a47546a8034cf0d94438ed746 6c97326.pdf. Accessed 14 Nov 2017.

Ghaderi, A., M.S. Jabalameli, F. Barzinpour, and R. Rahmaniani. 2012. An efficient hybrid particle swarm optimization algorithm 
for solving the uncapacitated continuous location-allocation problem. Networks and Spatial Economics 12(3): 421-439.

Hakimi, S.L. 1964. Optimum locations of switching centers and the absolute centers and medians of a graph. Operations Research 12(3): 450-459.

Hakimi, S.L. 1965. Optimum distribution of switching centers in a communication network and some related graph theoretic problems. Operations Research 13(3): 462-475.

Hu, F., W. Xu, and X. Li. 2012. A modified particle swarm optimization algorithm for optimal allocation of earthquake emergency shelters. International Journal of Geographical Information Science 26(9): 1643-1666.

Hu, F., S. Yang, and W. Xu. 2014. A non-dominated sorting genetic algorithm for the location and districting planning of earthquake shelters. International Journal of Geographical Informational Science 28(7): 1482-1501.

Huang, B., N. Liu, and M. Chandramouli. 2006. A GIS supported Ant algorithm for the linear feature covering problem with distance constraints. Decision Support Systems 42(2): 1063-1075.

Johansson, A., D. Helbing, H.Z. Al-Abideen, and S. Al-Bosta. 2008. From crowd dynamics to crowd safety: A video-based analysis. Advances in Complex Systems 11(4): 497-527.

Jonkman, S.N., B. Maaskant, E. Boyd, and M.L. Levitan. 2009. Loss of life caused by the flooding of New Orleans after Hurricane Katrina: Analysis of the relationship between flood characteristics and mortality. Risk Analysis 29(5): 676-698.

Kady, R.A. 2012. The development of a movement-density relationship for people going on four in evacuation. Safety Science 50(2): 253-258.

Kılc1, F., B.Y. Kara, and B. Bozkaya. 2015. Locating temporary shelter areas after an earthquake: A case for Turkey. European Journal of Operational Research 243(1): 323-332.

Koks, E.E., M. Bočkarjova, H. Moel, and J.C. Aerts. 2015. Integrated direct and indirect flood risk modeling: Development and sensitivity analysis. Risk Analysis 35(5): 882-900.

Kongsomsaksakul, S., C. Yang, and A. Chen. 2005. Shelter locationallocation model for flood evacuation planning. Journal of the Eastern Asia Society for Transportation Studies 6: 4237-4252.

Li, A.C., L. Nozick, N. Xu, and R. Davidson. 2012. Shelter location and transportation planning under hurricane conditions. Transportation Research Part E: Logistics and Transportation Review 48(4): 715-729.

Li, X., J. He, and X. Liu. 2009. Intelligent GIS for solving highdimensional site selection problems using ant colony optimization techniques. International Journal of Geographical Informational Science 23(4): 399-416.

Liu, C., Y. Fan, and F. Ordóñez. 2009. A two-stage stochastic programming model for transportation network protection. Computers \& Operations Research 36(5): 1582-1590.

Marinakis, Y., and M. Marinaki. 2008. A particle swarm optimization algorithm with path relinking for the location routing problem. Journal of Mathematical Modelling and Algorithms 7(1): 59-78.

Moussaï, M., D. Helbing, and G. Theraulaz. 2011. How simple rules determine pedestrian behavior and crowd disasters. Proceedings of the National Academy of Sciences 108(17): 6884-6888.

Ng, M., J. Park, and S.T. Waller. 2010. A hybrid bi-level model for the optimal shelter assignment in emergency evacuations. Computer-Aided Civil and Infrastructure Engineering 25(8): 547-556.

Pan, A. 2010. The applications of maximal covering model in typhoon emergency shelter location problem. 2010 IEEE international conference on industrial engineering and engineering management, 7-10 December 2010. https://doi.org/10.1109/ IEEM.2010.5674577.

Rodríguez-Espíndola, O., and J. Gaytán. 2015. Scenario-based preparedness plan for floods. Natural Hazards 76(2): 1241-1262.

Saadatseresht, M., A. Mansourian, and M. Taleai. 2009. Evacuation planning using multiobjective evolutionary optimization approach. European Journal of Operational Research 198(1): 305-314.

Sherali, H.D., T.B. Carter, and A.G. Hobeika. 1991. A locationallocation model and algorithm for evacuation planning under hurricane/flood conditions. Transportation Research Part B: Methodological 25(6): 439-452.

Toregas, C., R. Swain, and C. ReVelle, and L. Bergman. 1971. The location of emergency service facilities. Operations Research 19(6): 1363-1373.

Weber, A. 1929. Theory of the location of industries (trans: Friedrich, C.J. from Weber's 1909 book). Chicago: The University of Chicago Press.

Widener, M.J. 2009. Modeling hurricane disaster relief distribution with a hierarchical capacitated-median model: An analysis with extensions. Master's thesis. Florida State University, Tallahassee, FL 32306, USA.

Widener, M.J. and M.W. Horner. 2011. A hierarchical approach to modeling hurricane disaster relief goods distribution. Journal of Transport Geography 19(4): 821-828.

Wood, N.J., and M.C. Schmidtlein. 2013. Community variations in population exposure to near-field tsunami hazards as a function of pedestrian travel time to safety. Natural Hazards 65(3): $1603-1628$

Xu, W., Y. Ma, X Zhao, Y. Li, L. Qin, and J. Du. 2018. A comparison of scenario-based hybrid bilevel and multi-objective locationallocation models for earthquake emergency shelters: A case study in the central area of Beijing, China. International Journal of Geographical Information Science 32(2):236-256.

Yeh, W.C. 2009. A two-stage discrete particle swarm optimization for the problem of multiple multi-level redundancy allocation in series systems. Expert Systems with Applications 36(5): 9192-9200.

Yin, P., S. Yu, P. Wang, and Y. Wang. 2007. Multi-objective task allocation in distributed computing systems by hybrid particle swarm optimization. Applied Mathematics Computation 184: 407-420.

$\mathrm{Yu}$, J., and J. Wen. 2016. Multi-criteria satisfaction assessment of the spatial distribution of urban emergency shelters based on highprecision population estimation. International Journal of Disaster Risk Science 7(4): 431-429.

Zahran, S., D. Tavani, and S. Weiler. 2013. Daily variation in natural disaster casualties: Information flows, safety, and opportunity costs in tornado versus hurricane strikes. Risk Analysis 33(7): $1265-1280$.

Zhang, N., H. Huang, B. Su, and H. Zhang. 2013. Population evacuation analysis: considering dynamic population vulnerability distribution and disaster information dissemination. Natural Hazards 69(3): 1629-1646.

Zhao, X., W. Xu, Y. Ma, and F. Hu. 2015. Scenario-based multiobjective optimum allocation model for earthquake emergency shelters using a modified particle swarm optimization algorithm: a case study in Chaoyang District, Beijing, China. PLOS ONE 10(12): e0144455. 